\title{
La guerra irregular en Guerrero, 2007-2017
}

\section{The Irregular War in Guerrero, 2007-2017}

\author{
Teresa Santiago \\ Universidad Autónoma Metropolitana \\ santiagoropezao6@gmail.com \\ Carlos Illades \\ Universidad Autónoma Metropolitana \\ carlosillades@yahoo.com.mx \\ DOI: I0.2490I/rehs.v40iI57.363
}

\section{(c) 7 (i) (8)}

La guerra irregular en Guerrero, 2007-20I7 por Teresa Santiago y Carlos Illades se distribuye bajo una Licencia Creative Commons Atribución-NoComercial 4.o Internacional.

Fecha de recepción: 9 de octubre de 2017

Fecha de aprobación: 18 de mayo de 2018

\section{RESUMEN:}

No puede negarse que, desde su inicio, ha habido discrepancias en torno a qué tan legítimo es llamar "guerra" al combate contra el crimen organizado en México iniciado por Felipe Calderón Hinojosa. Y, sin embargo, tan sólo el hecho de tener desplegadas las fuerzas armadas en distintas regiones del país, de manera permanente y sin visos de que pueda ser relevado por policías debidamente adiestrados, de que a la fecha y haciendo un somero cálculo, podrían contarse en cientos de miles los muertos producidos por los enfrentamientos entre las propias organizaciones criminales y de éstas con la fuerza pública, de que ya hay decenas de miles de desplazados y desaparecidos, hace difícil encontrar otro término más adecuado que el de "guerra" para referirnos al presente, aun reconociendo que conlleva implicaciones y dificultades. Como ninguna entidad del país, Guerrero ha sido afectado por esta guerra por lo que, sirviéndonos de guerra irregular (una forma de la guerra interna), trataremos de entender esta faceta de su historia reciente.

Palabras clave:

Guerra irregular, operativos militares, víctimas, segurización. 


\section{ABSTRACT:}

There is no denying that from the very beginning, discrepancies existed over the legitimacy of using the term "war' to refer to the combat against organized crime in Mexico launched by Felipe Calderón Hinojosa. Yet the many terrible effects of this campaign make it difficult, indeed, to find a more adequate term than "war' to characterize it: the fact that the armed forces have been deployed permanently in different regions of the country with no sign of their imminent replacement by adequately-trained policemen; that even the most cursory calculation reveals that the number of deaths caused by clashes between criminal organizations and the forces of public order number in the hundreds of thousands; and that tens of thousands of innocent people have disappeared or been displaced. But no state in the country has been more terribly affected by this war than Guerrero, so this study seeks to understand this facet of the state's recent history by conceiving the fight against drug-trafficking as an irregular war; that is, a form of internal warfare.

Keywords:

Irregular war, military operations, victims, securitization.

Probablemente lo que va del siglo XXI han sido el periodo más violento de la historia contemporánea de México después del alzamiento de rgro. Contra la creencia de que cada roo años estalla una revolución en el país, esta vez la ola de violencia no se produjo por una insurrección popular, sino por la desafortunada estrategia adoptada por el Estado para combatir el narcotráfico que, tras el declive de los cárteles colombianos, erigió a los cárteles mexicanos en sus auténticos herederos. Fueron varios los factores que, en combinación, dieron lugar al surgimiento de círculos de violencia que se alimentan unos a otros reproduciendo el estado de guerra en que hoy nos encontramos y que no parecen poder revertirse en el corto plazo. Podemos enumerarlos en el orden siguiente: I) La secular connivencia de la política con los negocios pseudoilícitos o francamente ilícitos; 2) La normalización de la corrupción y la impunidad, entendidas como parte de nuestra idiosincrasia; 3) La debilidad de las instituciones, profundizada en la alternancia y el interregno panista; 4) El estancamiento económico que mantiene a la mitad de la población en situación de pobreza; 5) El sometimiento de los distintos gobiernos a la política de Estados Unidos en el combate a las drogas; 6) La precipitada decisión de lanzar una guerra de facto contra los cárteles de la droga sin tener un diagnóstico correcto, una estrategia adecuada y el aval del Congreso. ${ }^{\underline{1}}$

El is de diciembre de 2006, Felipe Calderón Hinojosa declaró la guerra a la delincuencia organizada. Comenzó por la patria chica michoacana, donde movilizó 6,500 soldados de infantería, apoyados por helicópteros y lanchas, además de difundir la desafortunada imagen de un presidente civil enfundando la casaca y el kepi militares. Al poco tiempo, los operativos se extendieron a Acapulco, Tijuana y la Sierra Madre, de manera tal que el despliegue de aproximadamente 50 mil elementos federales pronto alcanzó una docena de entidades. Tras un año, la administración calderonista logró extraditar a varios capos importantes a los Estados Unidos, además de conseguir el más importante decomiso de cocaína en la historia, alimentando enorme optimismo no sólo en su círculo cercano y en el empresariado mexicano, sino en el país 
vecino, lo que culminó con la Iniciativa Mérida para la Cooperación Bilateral contra la Delincuencia Organizada Transnacional en 2008.

Si la violencia comenzaba a crecer entonces en Guerrero, se achacaba a las células de los hermanos Beltrán Leyva. Sin embargo, la opción armada -la primera para un presidente neoconservador y no la última, como cabría pensarse en una sociedad moderna- pronto mostró sus límites. La lógica de la guerra provocó más violencia y la estrategia de descabezar los cárteles la multiplicó. La fragmentación de éstos, por la captura o abatimiento de sus líderes, potenció el conflicto de los grupos entre sí y la extorsión a la población civil, incrementándose todavía más los índices delictivos. La estrategia no varió con el regreso del pri al gobierno de la república y, en su desesperación, crecieron los dispositivos de autodefensa armada de la sociedad para hacer frente a la incapacidad manifiesta del Estado de hacerse cargo de la seguridad ciudadana.

Debemos reconocer, sin embargo, que en uno de los objetivos de la estrategia militar calderonista contra el crimen organizado se tuvo éxito, a saber, el descabezamiento de los principales cárteles. Pero esto que, en principio, parecería un gran logro, ha tenido como efecto la atomización de éstos y la formación de decenas de pequeñas bandas que, a lo largo del territorio nacional, asaltan, extorsionan, secuestran, roban combustible de los ductos que corren en el subsuelo; con el añadido de que no escatiman en el uso de la violencia ni contra quienes intentan proteger sus bienes, ni contra las organizaciones rivales. Esta violencia que se presenta en oleadas de distinta intensidad y que afecta directa o indirectamente a la mayoría de los mexicanos nos obliga a reflexionar sobre su naturaleza, sus consecuencias y los retos que impone a la convivencia presente y futura.

En sustento de lo anterior, se puede plantear la siguiente hipótesis: emplear las fuerzas armadas para combatir criminales comunes como si fueran contrainsurgencia provocó una guerra interna "irregular". En un combate de esta naturaleza se hace casi imposible aplicar las leyes de la guerra, esto es, los principios de contención del ius in bello. ${ }^{2}$ Y esto se refleja en el número de muertos, desaparecidos, desplazados y, en general, en los atropellos a los derechos humanos. Pero, además, esta guerra se ha ido degradando en cuanto a los medios que emplean las bandas criminales para mantener controladas las regiones en las que operan cuando entran en disputa, o bien, cuando se enfrentan al Ejército. El catálogo de atrocidades de las cuales dan cuenta los periódicos ha alcanzado una amplitud inaudita para un país que, supuestamente, no está en guerra; tan sólo combate a las mafias criminales en su propio territorio.

\section{Guerra irregular}

No puede negarse que, desde su inicio, ha habido discrepancias en torno a qué tan legítimo es llamar "guerra" al combate contra el crimen organizado en México emprendido por Calderón Hinojosa. Y, sin embargo, tan sólo el hecho de tener desplegadas las fuerzas armadas en distintas regiones del país, de manera permanente y sin visos de que puedan ser relevadas por policías debidamente adiestrados, de que a la fecha y haciendo un somero cálculo, podrían contarse en cientos de miles los muertos producidos por los enfrentamientos entre las propias organizaciones criminales y de éstas con la fuerza pública, de que ya hay decenas de miles de 
desplazados y desaparecidos, hace difícil encontrar otro término más adecuado que el de "guerra" para referirnos al presente, aun reconociendo que conlleva implicaciones y dificultades. Pero, además, hay otra razón de peso: es así como el presidente Nixon bautizó la cruzada para combatir la distribución y consumo de drogas en su país; emulando dicha política, Calderón Hinojosa adoptó el término.

Si bien para algunos, "a su manera se trata de una guerra civil", sólo lo es en la magnitud y la "intensidad de la violencia", pero no así en el hecho de que los bandos enfrentados no están claramente definidos, y el "campo de guerra", en donde se dan los enfrentamientos, obedece a la propia dinámica de cómo se disuelven y reagrupan las células criminales. ${ }^{3}$ Por otro lado, la guerra civil implica la fractura del Estado y el carácter irreconciliable de las diferencias políticas e ideológicas entre las partes enfrentadas. Hasta el momento, los grupos criminales que se disputan los negocios ilícitos no parecen estar ligados a alguna ideología política, aunque, sin duda, manejan no pocos símbolos identitarios en su manera de ejercer el dominio y la violencia, pero esto pertenece más a una cuestión de índole cultural, que a un posicionamiento político.

A pesar de estas objeciones, hay quien ofrece argumentos en favor de la idea de que se trata de una guerra civil económica, no política, que es el rasgo característico que habíamos señalado. Para Andreas Schedler, definirla así "es una elección conceptual que se sostiene fundamentalmente en cuatro argumentos": el primero de éstos, llamado "conceptual" apela a una definición muy amplia de guerra civil, "grupo armado dentro de un Estado", o bien de un grupo contra el Estado "que causa un mínimo de mil muertos al año". En el segundo argumento, de carácter "empírico", sostiene que las guerras civiles, sean políticas o económicas se "mueven con una lógica semejante". El aspecto ideológico no es sustancial a ninguna de éstas, tan sólo es accidental. El tercer argumento, "teórico", resalta la ventaja "analítica" para el caso de la guerra en México: "hay muchas cosas que podemos aprender de la literatura sobre guerras civiles. Junto a las diferencias profundas que existen entre violencia política y económica, también hay similitudes profundas". Finalmente, el argumento "político", enfatiza que esta guerra es interna, esto es, el conflicto y la violencia desatada se gestó internamente; el enemigo no vino de fuera a poner en peligro a las familias mexicanas, como el discurso oficial parece sugerir. Coincidimos con varios de los elementos señalados en estos argumentos sobre las similitudes existentes entre la guerra civil y la guerra interna, sin embargo, desde nuestro enfoque, el carácter político que define a la guerra civil no tiene un carácter accidental, sino esencial para distinguir distintos tipos de conflictos bélicos al interior de un Estado. ${ }^{4}$

Autores como Sergio González Rodríguez centraron la atención en la dimensión geopolítica de la guerra contra las drogas, destacando la intervención de los Estados Unidos no sólo en el flujo internacional de los estupefacientes sino su agenda oculta en materia de control imperial sobre México. En esta lógica -subraya el ensayista- la guerra no tendría el fin de acabar con la exportación de drogas al vecino del norte, antes bien sería un mecanismo permanente de intervención externa para hacerse de los recursos estratégicos del país. Visto así, "la meta es acrecentar la inestabilidad en México, para imponer el Estado 'fuerte' y la misión de que México actúe como gendarme de la región al sur de los E.U.A., Centroamérica y el Caribe". 5 Sin desestimar el componente de verdad que posee su tesis, ésta soslaya tanto la preocupación 
estadounidense por disminuir el flujo de drogas hacia su territorio, como la dinámica de la guerra interna mexicana.

También se ha caracterizado a esta guerra como "insurgencia criminal o narcoinsurgencia", tomando en cuenta el riesgo que representa para el Estado. En efecto, algunos estudiosos del fenómeno consideran que el término se ajusta puesto que "insurgencia" se define como "un movimiento organizado dirigido a derrocar un gobierno constituido, a través de la subversión y del conflicto armado". Pero no es menor la diferencia entre poner en peligro al Estado y estar encaminado a derrocar el poder instituido. Por muy poderoso que sea, el negocio del narco no tiene como objetivo principal derrocar al régimen, sino más bien incrustarse en él, según la tesis de Aguilar Camín. Siendo su razón de ser el máximo beneficio, las ganancias tienen que ser lavadas e invertidas, en suma, deben circular para que el negocio funcione, lo que no sería posible sin instituciones de todo tipo, tanto privadas como estatales. Una propuesta más aceptable que va en este sentido es el de "insurgencia comercial". $\underline{6}$

Otro enfoque, a nuestro juicio más plausible, se concentra sobre todo en las estrategias estatales para enfrentar al crimen. De acuerdo con éste, la guerra contra el narcotráfico no obedece a su objetivo explícito, posee el propósito tácito de ser una guerra social, contra los pobres, a fin de despejar el terreno para la expansión capitalista. En esta línea, el Estado sirve como punta de lanza de los negocios privados y privilegia la estrategia de "segurización". Con lo cual el combate al crimen "ha proporcionado -sostiene Gledhill- el pretexto para una participación militar más profunda en la labor policial". Ello potencia el autoritarismo de un Estado que no se ha despojado de ese atributo inherente a su origen y acrecienta la violación de los derechos humanos de la población civil. Llevado al extremo -nos dice Agamben- "una democracia limitada a disponer como único paradigma de gobernación, y como único objetivo, el Estado de excepción y la búsqueda de la seguridad [...] deja de ser una democracia".

A esto es lo que nosotros llamamos "la otra guerra" hace cuatro años. El saldo oculto de la narcoguerra que, en la vorágine de la violencia, liquida -con la complicidad del Estado o ante su conducta omisa- a líderes sociales, defensores de los derechos humanos y periodistas. Desde nuestra perspectiva, y empezando por lo más obvio, la narcoguerra es una guerra interna y no extraterritorial, esto es, el enemigo que se enfrenta es un enemigo interno, si bien difuso en la medida en que es difícil identificarlo y ubicarlo. Además, hablamos de una guerra "irregular" en la cual el Ejército no se enfrenta a otro ejército, sino a bandas armadas -esto es, ejércitos particulares- con la misma, y en ocasiones, mayor capacidad de respuesta que, no obstante, son combatidas con el modelo de la contrainsurgencia, es decir, como si los grupos delincuenciales fueran grupos rebeldes. Se trata también de un tipo de las llamadas "nuevas guerras" que, según la definición de Mary Kaldor se diferencian de las guerras convencionales tanto "en sus objetivos, como sus métodos de lucha y sus modos de financiación". Pero, sobre todo, son guerras en las cuales las distinciones tradicionales entre "la barbarie externa y el civismo interno, entre el combatiente legítimo y el no combatiente, entre el soldado o policía y el criminal", se están desdibujando. En este mismo sentido, Achille Mbembe resalta que cada vez son más frecuentes las guerras no entre Estados, "sino entre grupos armados que actúan bajo la máscara del Estado pero que controlan territorios bien delimitados".. Y aun cuando no se puedan hacer de todo el 
poder sí llegan a dominar territorios completos, "feudos", en los cuales controlan la extracción de minerales (esto, sobre todo en África), o bien, como en el caso de México, plantíos de enervantes, aunque también se han extendido a otros rubros.

Expresión del carácter irregular de la guerra es que los enfrentamientos "tienden a ser intermitentes", no existen líneas o frentes precisos de combate, ${ }^{\circ}$ éstos se definen por el recrudecimiento de la violencia ocasionada por la lucha entre cárteles o bandas enemigas que se disputan un territorio, una plaza, o bien un circuito del trasiego de droga. El ejército puede ser desplazado del norte del país al centro, o bien a las ciudades costeras, de acuerdo con la gravedad de la situación. Sin embargo, las operaciones militares no consiguen del todo la pacificación, sino tan sólo la interrupción temporal de la violencia.

A diferencia de las guerras convencionales, es decir, aquellas en donde el objetivo es el avance territorial para reducir el espacio y así debilitar al enemigo, en ésta la ocupación territorial no es síntoma de que se avance en ese sentido. Una de las razones es que los grupos delincuenciales logran en no pocas ocasiones insertarse en las comunidades al compartir los beneficios del negocio; el dominio que ejercen no sólo es territorial sino social e incluso político. O bien atemorizando a la comunidad por medio de amenazas muchas veces cumplidas que llevan a ejecuciones y masacres de familias enteras. Es así como en una misma comunidad o ciudad pueden coexistir las fuerzas del orden y los grupos delictivos, no hay verdaderas "tomas" o recuperación por parte de aquéllas. La diversificación de los negocios ilícitos, pues, ya no sólo es el narcotráfico, ha hecho aún más patente la imagen de que el Estado mexicano libra una batalla contra un enemigo difuso, ubicuo y con un poder corruptor sin límites.

Pero incluso esta afirmación sólo sería exacta si concebimos al Estado como un ente monolítico que actúa en consonancia de todas sus partes. La realidad es que esto no es así. La globalización ha provocado el debilitamiento del Estado weberiano cuya función principal era el monopolio de la violencia legítima. Los nuevos actores, sean mafias internacionales, cárteles de la droga, señores de la guerra o bien combinaciones entre éstos, le disputan al Estado ese patrimonio, mermando con ello su capacidad de respuesta e incluso su legitimidad. Una idea alternativa que puede ayudar a entender mejor cómo se comportan los actores institucionales frente a la amenaza que representa el poder de los negocios ilícitos es la caracterización que ofrece Migdal del Estado, en primer lugar, como un campo en donde se disputa el poder y las normas con otros actores de la sociedad y, al mismo tiempo, como un conjunto de prácticas normalizadas pero renovables. La primera idea pondría en evidencia las limitaciones de la idea del Estado como "monopolio" de la violencia legítima. El Estado permanentemente está en disputa de ese monopolio con otros grupos sociales que pueden asumirse como contendientes legítimos porque han ganado reconocimiento social y o político. La segunda tesis (el Estado compuesto por una imagen y un conjunto de prácticas) también resulta iluminadora: debemos abandonar la creencia de que el Estado siempre impone sus reglas (como dicta cualquier definición estándar), siendo que, en realidad, las conductas de los diferentes actores sociales no corresponden (a veces en absoluto) con la imagen que tenemos del Estado y las instituciones. 
Combatir al crimen organizado por medio de la militarización parte de una premisa equivocada, pues, no existe una línea clara entre el interior y el exterior, lo público y lo privado que pudiera señalar en dónde exactamente se encuentra el enemigo. Este error de perspectiva ha tenido consecuencias muy graves para la sociedad mexicana en su conjunto, algunas de las cuales deben ser evidenciadas. No solamente es muy cuestionable que el Ejército combata delitos del fuero común, sino que los propios soldados no estén capacitados para enfrentar a esa clase de enemigo y, por tanto, cometan abusos contra la población civil, además de que ellos mismos pueden considerarse como víctimas al ser empujados a una guerra para la cual no han sido entrenados. Otra consecuencia indeseable es la dificultad de aplicar principios de contención en los operativos militares. Tanto el principio de discriminación entre combatientes y no combatientes, como el de proporcionalidad entre el objetivo y los medios para lograrlo, pertenecientes a la tradición de la guerra justa, pero asimilados por las convenciones de guerra del derecho internacional, se espera que regulen la conducta de guerra en conflictos interestatales. Tratándose de guerras irregulares, como es el caso del combate al narcotráfico, las guerrillas y la insurgencia, no hay manera de vigilar u obligar a las partes en pugna para que estos principios sean respetados, pues "national military forces face certain obvious difficulties: they often cannot identify their enemies, [...] [they] do not wear uniforms, they look like innocent civilians; they often choose to fight in places where real innocents are found in large numbers". oㅡ Además de numerosas violaciones a los derechos humanos.

Similares problemas se presentan con relación al principio de proporcionalidad, según el cual, la fuerza empleada para conseguir un objetivo específico no debe ser desproporcionada respecto de éste. En otras palabras, prohíbe la fuerza y la violencia innecesaria, algo extremadamente difícil si no es que imposible frente a enemigos tan poderosos como son los cárteles de la droga. Dada la facilidad para conseguir armas de todo tipo y calibre, las diferentes ramas del crimen organizado (salvo las pequeñas bandas de narcomenudistas) están muy bien pertrechadas y cuentan además con cuantiosos recursos para adquirirlas. El poderío de armamento es consustancial a los grupos criminales. Estar preparados para combatir al rival o bien al Ejército y otras fuerzas federales es una prioridad. A su vez, éste también ha tenido que actualizarse y proveerse de equipo como no lo hacía desde décadas atrás. Pero en esta lógica, lo único que se puede esperar es o bien una suma cero, o bien el escalamiento a la guerra total según la idea de Clausewitz, en la cual resultan fútiles todos los principios de contención de las leyes de la guerra o ius in bello.

La imposibilidad de medirse cara a cara con los criminales organizados en verdaderos ejércitos compactos ha llevado a optar por la estrategia de ir por los capos más visibles, tarea que ha resultado bastante exitosa en el papel. En la práctica, el descabezamiento ha provocado la diseminación y atomización de los grandes cárteles en bandas criminales con una enorme capacidad de respuesta. Como verdaderas células vivas constantemente se dividen y reorganizan. Esto no significa, sin embargo, que las pandillas o bandas suplanten a los cárteles. Más bien se

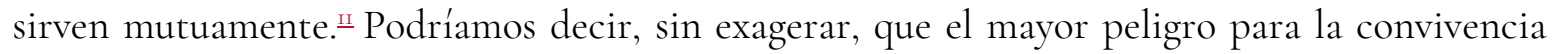
social en el México actual lo representa la violencia producida por esta proliferación de bandas criminales que no sólo trafican droga, sino también extorsionan, secuestran, roban combustible y blanquean dinero a través de múltiples negocios. 
Los señores de la guerra

Como expusimos en Estado de guerra, la guerra contra el crimen organizado germinó en el terreno fértil de la contrainsurgencia con que se hizo frente a las guerrillas. En ésta, el Estado utilizó todos los recursos disponibles (lícitos e ilícitos) para acabar con los grupos armados. La discrecionalidad con que actuaron los órganos de seguridad estatales, en el marco del régimen autoritario, propició numerosas violaciones de derechos humanos, ejecuciones clandestinas y el arrasamiento de poblados en la Sierra de Atoyac y la Costa Grande guerrerenses. Y, en lugar de que estos delitos se sancionaran, algunos de los responsables de la contrainsurgencia recibieron encomiendas gubernamentales cuando ésta se transformó en guerra sucia. La administración de Rubén Figueroa Figueroa (I975-I98I) habilitó como operador de ésta al siniestro mayor Mario Arturo Acosta Chaparro Escápite, primero como delegado de Tránsito, después, como jefe de la policía de Acapulco, y más adelante, a cargo de la seguridad en toda la entidad. El mayor tenía a su mando directo cuatro grupos policíacos. Al militar del cuerpo de paracaidistas se le responsabiliza de la operación de una cárcel clandestina en un sótano de la Dirección de Tránsito de Acapulco, de torturar y asesinar a detenidos en el fraccionamiento Copacabana (Punta Diamante), además de poner en marcha los "vuelos de la muerte" desde la Base Aérea Militar número $7 . \frac{12}{}$ De esta manera comenzó a borrarse la línea entre la policía y el crimen en la entidad suriana.

Mientras tanto, en la sierra guerrerense crecía el cultivo histórico del cannabis y el más reciente de la amapola, a causa del aumento de la demanda en los Estados Unidos. Ya en I97i, Nixon había decidido que eso no era bueno para los muchachos de su país, por lo que emprendió la guerra contra las drogas y de paso aprovechó para acabar con las guerrillas latinoamericanas. Cinco años después, la Operación Cóndor, coordinada del lado mexicano por el general José Hernández Toledo, movilizó ro mil soldados hacia Sinaloa, Chihuahua y Durango para destruir los sembradíos de droga. No acabaron con ellos, pero sí provocaron el desplazamiento de agricultores y trabajadores agrícolas al dañarse severamente sus tierras por los exfoliantes. En un desplante, el general Toledo pronosticó "el fin del narcotráfico en seis meses". 푼

En el régimen priista la soberanía descansaba en el poder central del Estado y los gobiernos estatales y municipales administraban los recursos compartiendo, pero también poniendo límites, a los negocios ilícitos, tales como el narcotráfico. No es que no hubiera grupos delincuenciales, pero se les mantenía controlados gracias a arreglos tácitos con las autoridades que actuaban como intermediarios, ciertamente bajo una cadena de mando. La "feudalización" del poder político tras la alternancia, modificó el modelo presidencialista-soberanista; los gobiernos locales, sobre todo, los municipales ya no funcionaron como mediadores. Con el cambio en las relaciones de subordinación y el debilitamiento de los controles, así fueran mínimos, "las organizaciones criminales entraron en un proceso de lucha violenta por la hegemonía en el campo criminal". De otro lado, México se abrió como ningún otro país latinoamericano al mercado global comenzando con la administración de Miguel de la Madrid y seguido por el TLCAN. Por una frontera de 3 mil kilómetros se multiplicó el tráfico de todo tipo de mercancías, incluyendo drogas y armas. ${ }^{14}$ De esta forma, además de la explotación tradicional y exportación de la marihuana guerrerense -la acreditada Acapulco Gold-, la entidad 
suriana sería lugar de paso de la cocaína. Posteriormente vendrían las drogas sintéticas y el auge de la heroína, al tiempo que el campo mexicano entraba en una crisis profunda.

Gráfico r. Cultivo de amapola en México 2005-2015

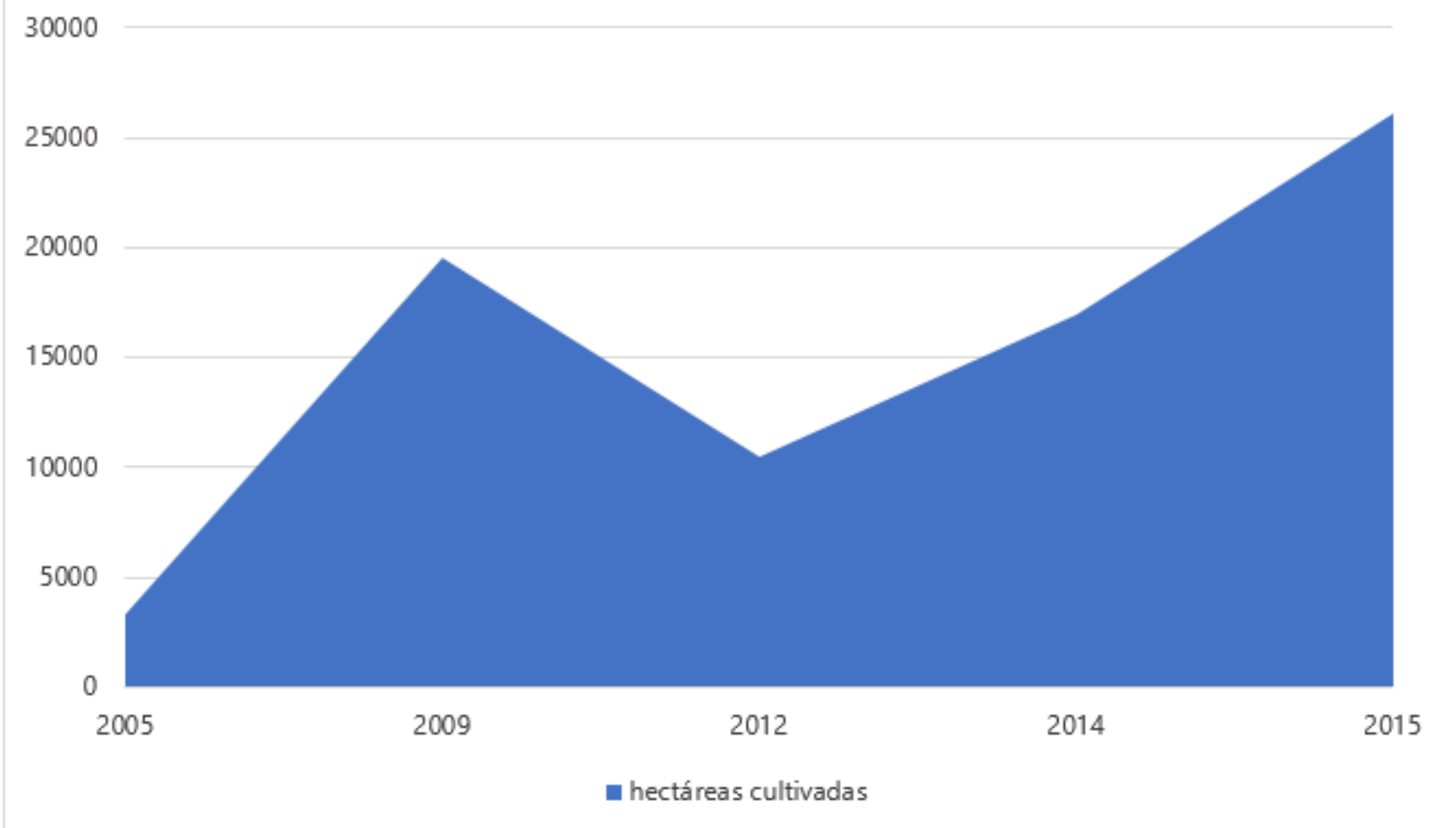

Fuente: UNDOC, World Drug Report. Market analysis of plant-based drugs. Opiates, cocaine, cannabis.Viena: ONU, 20I7,I4.

En 2015, México figuraba como el tercer productor mundial de opio y el segundo de marihuana. De 2000 a esa fecha, el Ejército destruyó el equivalente a I29,I46 hectáreas de amapola y a poco más de 30,9ro hectáreas de marihuana en Guerrero, lo que da idea del inmenso botín disputado por los cárteles. Por lo que recién señalamos, el estado sureño ofreció las condiciones idóneas para que ahí se extendiera la organización criminal que llegó a ser la más poderosa de la década al decaer los cárteles colombianos: el cártel de Sinaloa; su aliado local lo conformó el grupo de los hermanos Beltrán Leyva. Las ganancias exorbitantes pronto llamaron la atención de otras organizaciones delictivas rivales: la intromisión del Cártel del Golfo y de su brazo armado los Zetas tenía que ser repelida y para ello se creó el grupo de contraataque los Pelones, comandado por el después famoso Edgar Valdés Villareal, alias la Barbie. Ésta fue la primera ola de violencia que sufrió el estado entre los años 2004-2006 que, sin embargo, no elevó significativamente el número de muertes en la entidad, sobre todo, en comparación con los años por venir. No obstante, en abril de 2006 se dio un primer signo ominoso de la inseguridad: en la intersección de la Garita en donde se había librado un enfrentamiento entre la policía municipal y los Pelones, aparecieron las cabezas del comandante Mario Núñez Salgado y Erick Juárez Martínez, 
policía municipal, con un narcomensaje dirigido a las autoridades "para que aprendan a respetar". De acuerdo con un registro, sumaron 548 cuerpos mutilados recobrados por las autoridades en los años subsiguientes. .5

Estamos ciertos que las alianzas entre los cárteles de la droga son perentorias. Y la ruptura del Cártel de Sinaloa con los hermanos Beltrán Leyva escalaría violencia. De esta escisión van a salir varias organizaciones criminales como el Cártel Independiente de Acapulco, empeñado en arrebatarle al de Sinaloa el puerto, para lo cual habría de enfrentarse con el filial de éste en el Pacífico, el grupo de la Barredora. Acapulco se convirtió en la ciudad más peligrosa del territorio nacional, afectando drásticamente la economía guerrerense dependiente del turismo. En 20i7, la zona metropolitana de Acapulco alcanzó un promedio de iI4.2 ejecuciones por cada mil habitantes. En los años recientes han cerrado sus puertas unos 2,0oo negocios debido a la violencia y a la extorsión. La policía local, rebasada por la ola criminal, mal pagada y con escasas garantías laborales entró en huelga en abril de 20I4. Durante meses fueron el Ejército, la Policía Federal y la recién creada Gendarmería quienes se ocuparon de la seguridad del puerto, con el cometido principal de proteger al turismo. No pocos esfuerzos se han hecho para limpiar a la policía municipal sin que se traduzcan en resultados visibles. Un supervisor de la policía de Acapulco declaró no hace mucho que "la policía municipal no trabaja para el crimen organizado; la policía municipal es el crimen organizado". $\underline{\underline{6}}$

Gráfico 2. Homicidios dolosos en el municipio de Acapulco de Juárez, 2009-20i6

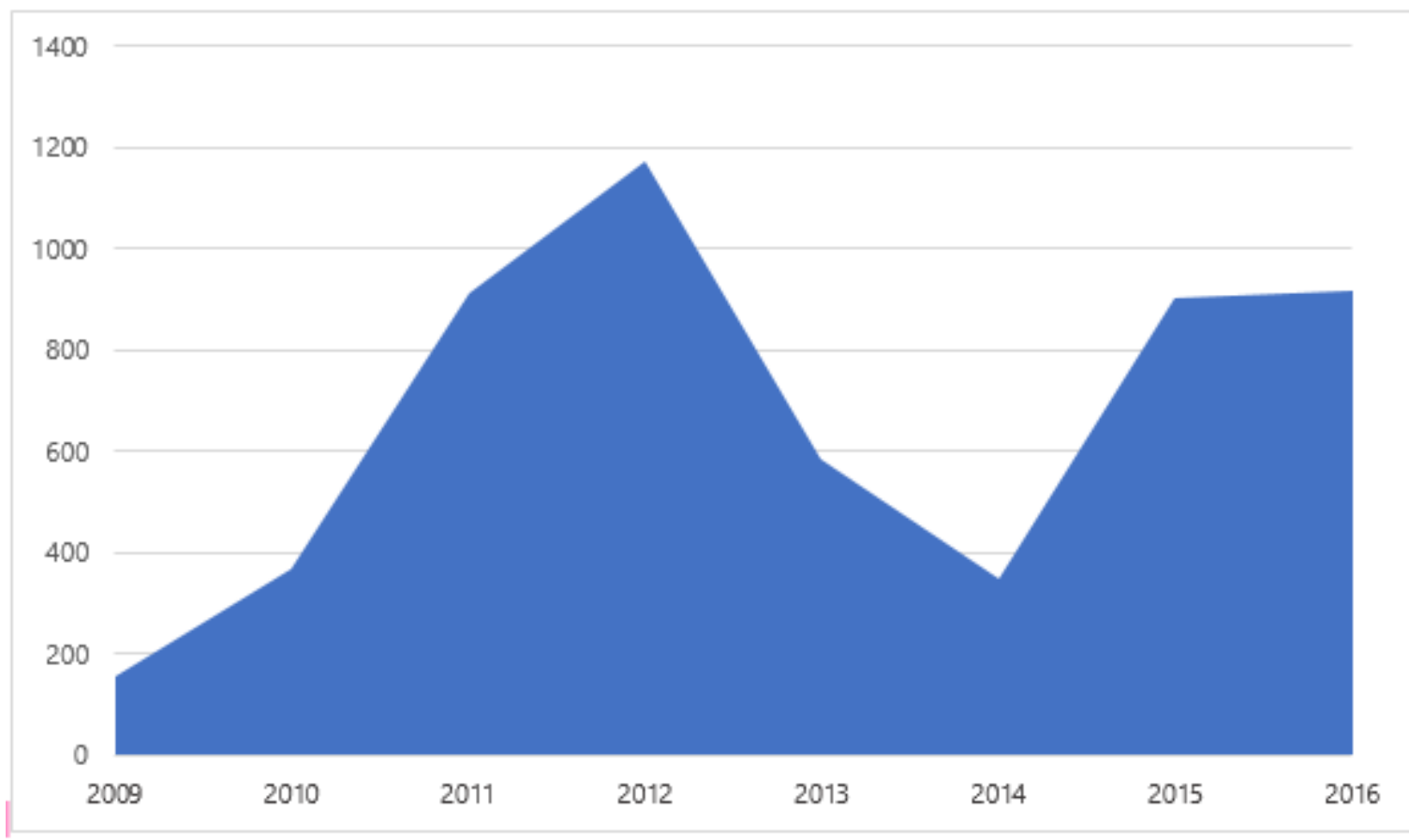

Fuentes: Eduardo Guerrero Gutiérrez, "La raíz de la violencia", Nexos, en línea, junio de 20II; Eduardo Guerrero Gutiérrez, “Bajó la violencia?”, Nexos, en línea, febrero de 20I5;

"Las 50 ciudades más violentas del mundo; 9 son mexicanas", Aristegui Noticias, 7 de febrero de 20i3; "Acapulco, Tijuana y Culiacán, los municipios con más homicidios en 
2015", Animal Político, 28 de mayo de 2016; "En Guerrero, 2 mil 2rз asesinatos en 2016, casi Io \% más que en 2015; siguió primero en el país", El Sur, en línea, 23 de enero de 2017.

El desmembramiento del cártel de los hermanos Beltrán Leyva modificó el panorama del crimen en el territorio guerrerense a partir de 2009 esparciéndose bandas delincuenciales pequeñas y violentas, sin las conexiones políticas y la amplia red de negocios de los cárteles de donde procedían. Esta recomposición marca una nueva ola de violencia en el Estado, además de una diversificación del negocio ilícito. Siendo menos poderosas en términos políticos, y cada vez más competido el negocio de las drogas, las bandas delincuenciales tienen que obtener ganancias de otras actividades tales como el secuestro, la extorsión, el derecho de piso. Actividades todas que incrementan y "especializan" la violencia. Las nuevas organizaciones son más violentas y producen más muerte no por casualidad o por ser sus miembros naturalmente más crueles. El tipo de negocio al que se dedican, además del narcotráfico, es impracticable sin la "sofisticación" de la violencia. Cultivar amapola, procesarla para sacar la goma de opio, trasladar la mercancía a los centros de acopio y distribución, puede ser una actividad riesgosa, pero no implica necesariamente emplear métodos violentos, salvo cuando se tienen que defender territorios, plazas y rutas. Es entonces cuando las bandas secuestran y extorsionan, lo que se hace imposible si no se recurre a la amenaza más fuerte que puede haber: la muerte propia o la de los cercanos. Siendo así, la violencia discursiva del narcotráfico se revuelve con la violencia pandillera, "más intensa y difícil de controlar porque las matanzas forman parte de la afirmación identitaria de estos grupos delictivos". ${ }^{17}$

Estas formas de la violencia criminal son las que más afectan a la población civil; tanto la extorsión como el cobro de piso son delitos difusos porque a pesar de que se sabe que operan en prácticamente todas las ciudades del estado, el índice de denuncias es menor a la incidencia por el peligro que conlleva. Mientras que, en el caso del secuestro, un indicador para identificarlo y contabilizarlo son las fosas clandestinas en donde se han descubierto cientos -si no es que milesde restos humanos.

Cuando menos operaban 22 bandas criminales en Guerrero en 2014, muchas provenientes del cártel de los Beltrán Leyva. El Cártel Independiente de Acapulco; los Rojos, en todo el estado, pero fundamentalmente el centro, el norte y la Montaña; Guerreros Unidos, a lo ancho de la entidad, pero concentrados en el norte y la Tierra Caliente; los Ardillos, en Quechultenango, Mochitlán y Tixtla; la Familia Michoacana, penetrando por la Tierra Caliente y por la ruta Lázaro Cárdenas-Zihuatanejo. Estos grupos dominaron el paisaje criminal suriano la segunda década del siglo XXI hasta partirse en grupos más pequeños y agresivos. En permanente disputa Guerreros Unidos combatió en Tierra Cliente -principalmente en Teloloapan- con la Familia y, más tarde, los Templarios; y en Taxco e Iguala con los Rojos, por el trasiego de la goma de opio procedente de la sierra. Y en Tixtla, Chilapa y Tlapa, los Rojos pelearon a muerte con los Ardillos. En estas zonas, como en el corredor Río Balsas, Chilpancingo, Ocotito, son frecuentes los choques entre los grupos criminales, pues, son los caminos que conectan con las zonas de producción de la amapola en Filo Mayor, Leonardo Bravo y Eduardo Neri, además de formar parte del Cinturón de Oro. $\frac{18}{}$ 
Con su bastión en Iguala, los Guerreros Unidos fueron el resultado del reagrupamiento de sicarios de distintos grupos delincuenciales que quedaron sueltos con la fragmentación de los cárteles. Comandados por Mario Casarrubias Salgado, antiguo escolta de Arturo Beltrán Leyva, se le conoce con aquel nombre desde 20I2, cuando capturaron a su antiguo líder, Toribio Rentería, y el Sapo Guapo se hizo cargo de la organización. La Marina detuvo a Casarrubias Salgado en abril de 2014, y su hermano Sidronio y Salomón Pineda Villa ocuparon su lugar. Los hermanos del Salo dirigieron la banda conocida como los Pelones, al servicio de Beltrán Leyva, y su hermana María de los Ángeles es esposa del exalcalde de Iguala José Luis Abarca. El jefe regional de los Guerreros Unidos era Gildardo López Astudillo, el Cabo Gil, uno de los responsables de la desaparición de los estudiantes de Ayotzinapa. ${ }^{19}$

La diligencia ministerial por la noche de Iguala abunda en referencias a la disputa por la plaza entre los Guerreros Unidos y los Rojos: "eran del cártel de los Rojos", "se habían metido los Rojos", "vienen de los contras de los Rojos a pelear la plaza". El grupo criminal tomó su nombre de Jesús Nava Romero, el Rojo, abatido junto con Arturo Beltrán Leyva en 2009. Pero fue el sobrino de aquél, Jesús Nava Marino, quien creó el Cártel de la Sierra (después los Rojos) como una organización independiente. A Nava Merino lo asesinaron en Iguala en octubre de 20 Io y Crisóforo Rogelio Maldonado Jiménez, el Bocinas, ocupó su lugar. Tras su ejecución en 2012 en un hospital privado del sur de la Ciudad de México, su esposa María del Carmen Nava Romero y los hermanos de ella (José y Leonor) se hicieron cargo de la banda desde su centro de operaciones en Chilpancingo. José murió en Puebla en 2013 y, al año siguiente, detuvieron a Leonor y María del Carmen en acciones separadas. $\underline{20}$

Si con los Guerreros Unidos los Rojos disputaban el norte de la entidad y Morelos, con los Ardillos los Rojos riñeron por la Montaña y también por la ruta que baja de ésta hacia la costa, zona que, es importante destacar, confrontó reiteradamente a dos grupos de autodefensa ciudadana entre sí como veremos más adelante. Cuando menos en lo que va del siglo la familia Ortega Rosas ha estado involucrada en actividades criminales. Comenzó con el secuestro y la extorsión, saltó después al narcotráfico, pero sin abandonar los otros giros delincuenciales. El grupo lo fundó en Quechultenango, Celso Ortega Rosas, la Ardilla, asesinado en 20Ir. Tras el homicidio del jefe, el liderazgo de la banda pasó a manos de sus hijos Celso y Antonio Ortega Jiménez. El hermano de éstos, Bernardo Ortega Jiménez, fue presidente municipal de Quechultenango (2002-2005), diputado local (2005-2008 y 2012-2015). Miembro de la corriente perredista Nueva Izquierda (los Chuchos), Ortega Jiménez fue diputado en la LX Legislatura y coordinó la fracción parlamentaria de su partido, además de ser presidente del congreso del estado. Para muchos el exdiputado es el brazo político del clan..

En mayo de 20I5, escaló el conflicto entre Rojos y Ardillos. La madrugada del 9 irrumpieron en Chilapa 300 hombres armados -autoidentificados como autodefensas, pero según la vox populi Ardillos- y tomaron la ciudad, desarmaron a los municipales, robaron armamento, instalaron retenes, "levantaron" a I2 o más personas (taxistas, vendedores, carniceros, estudiantes, activistas) y patrullaron la ciudad en sus camionetas y los vehículos oficiales de que se hicieron para capturar a Zenén Nava Sánchez, el Chaparro, líder de los Rojos. Al quinto día corrió el rumor de que un comando de los Rojos llegó a recuperar la plaza. Aterrorizada, la 
población permaneció en sus casas. Los comercios cerraron. El alcalde priista apodado el Tepache de plano abandonó la ciudad que debía gobernar. Como si fueran "Cascos Azules", las fuerzas federales se concretaron a impedir un enfrentamiento entre los grupos criminales. Antes de concluir la semana los mandos militares y de la policía estatal pactaron con las supuestas autodefensas que éstas abandonarían el poblado mientras ellos se comprometían a capturar a los Rojos incrustados en Chilapa. Desde entonces, el pueblo de la Montaña Baja no ha vuelto a estar en paz, no hay detenidos "y sin que alguno de los que se los llevaron aparezca". De acuerdo con la madre de uno de ellos, "los Ardillos los obligan a trabajar en las actividades ilícitas, según las investigaciones que ella misma ha hecho". ${ }^{22}$

Lejos de allí, en la Tierra Caliente ocurre algo similar, es la tierra del Tequilero. Primero dominada por los Beltrán Leyva pese a los intentos de los Zetas por despojarlos del control de las rutas hacia Michoacán y la Costa Grande guerrerense. Tras el eclipse de los Beltrán Leyva, fue la Familia Michoacana la que se apoderó de la próspera región comercial. Posteriormente el desafío provino de los Caballeros Templarios (escindidos de la Familia Michoacana) y del Cártel Jalisco Nueva Generación (CJNG), que presionaban desde el occidente, y de los Rojos y particularmente de los Guerreros Unidos, por el este. También surgieron bandas independientes como la del Tequilero, Raybel Jacobo de Almonte, quien desde finales de 2014 comenzó a operar al margen de La Familia Michoacana, aunque de acuerdo con otra versión el grupo criminal proviene de los Granados, asentados en San Luis la Loma y aliados en algún momento con los Beltrán Leyva. ${ }^{23}$

En julio de 20I6, emboscaron y asesinaron en la frontera michoacana al presidente municipal de Pungarabato (Ciudad Altamirano), el perredista Ambrosio Soto Duarte, y a su chofer, resultando heridos dos agentes federales. El munícipe había denunciado tres semanas atrás amenazas de muerte por parte de un grupo criminal, posiblemente para cobrar piso a las exiguas arcas de la alcaldía. En agosto, un comando armado secuestró al regidor de Seguridad Pública de San Miguel Totolapan. En noviembre, los Tequileros efectuaron un secuestro masivo en San Jerónimo, Ajuchitlán del Progreso. Entre los i2 o I4 levantados había menores de edad. En diciembre la banda privó de la libertad al ingeniero Isauro de Paz Duque, presuntamente para cobrar un rescate. En respuesta, una autodefensa local, recién formada para repeler las irrupciones tequileras, secuestró a la madre de Jacobo de Almonte. Tras una complicada negociación en la que medió el gobierno estatal, ambos fueron liberados. Junto con la madre del Tequilero, la autodefensa capturó a 20 miembros de la organización criminal, los cuales entregó al gobierno estatal. Únicamente cuatro quedaron sujetos a proceso. En abril de 20r7, el alcalde de Teloloapan abandonó el poblado por amenazas de muerte de los Tequileros. Distintas fuentes, vinculan a la banda de Jacobo de Almonte con el diputado local de extracción priista Saúl Beltrán Orozco. $\underline{24}$

Rogaciano Alba Álvarez, el Roga, fue el cacique indisputado de Petatlán hasta que cayó en desgracia en 20ro. Compadre de Rubén Figueroa Alcocer, ligado con el cártel de Sinaloa, líder de la Unión Regional Ganadera de Guerrero, militante priista, presunto autor intelectual del homicidio de la activista Digna Ochoa, el exalcalde se apropió impunemente de las tierras de la Sierra de Petatlán, después que la lucha de los campesinos locales rindió frutos al lograr que la 
empresa maderera Boise Cascade abandonara la región. Cuando los Beltrán Leyva rompieron con el Chapo Guzmán, el Roga, se inclinó por éste pese a la invitación de aquéllos para que se volviera el jefe de la plaza de Zihuatanejo. La represalia en su propio bastión fue atroz: un grupo de 60 sicarios dio muerte a 9 personas, entre ellas dos de sus hijos, y raptaron a una de sus hijas. Ultimado Arturo Beltrán Leyva, y presos Alba Álvarez y Rubén Granados Vargas, con el objeto de contener la invasión de la Costa Grande por parte de los Caballeros Templarios, en 2014 el grupo del Roga y los Granados se asociaron con el CJNG y formaron un nuevo grupo regional conocido como la Guardia guerrerense. 55

\section{Guerrero (in)seguro}

Con la Operación Conjunta Guerrero de enero de 2007, los habitantes del estado vieron llegar agentes de la ahora extinta Agencia Federal de Investigaciones, del Centro de Investigación y Seguridad Nacional y de la Policía Federal Preventiva. Se reforzó también la presencia de soldados del Ejército y la Marina. En total, se movilizaron 7,6oo efectivos de estas corporaciones. La estrategia consistió en instalar retenes sobre las entradas y salidas de las carreteras de mayor circulación, las que llevan a Chilpancingo, Acapulco y Zihuatanejo. También se confiscaron y destruyeron 4 mil cultivos de enervantes. A final de cuentas, la Operación Conjunta Guerrero fue un fracaso y, para octubre 2oII, el secretario de gobernación Francisco Blake Mora, se vio precisado a reconocer que "el número de personas asesinadas y hechos vinculados con el crimen organizado, se incrementó un cien por ciento en todo Guerrero y 300 por ciento en Acapulco". ${ }^{2}$

Pero el revés no condujo a rectificar la estrategia, antes bien llevó a profundizarla. El Operativo Guerrero Seguro de zori se implementó con el fin de que las fuerzas federales se ocuparan de la seguridad de la entidad mientras se hacía la depuración de las policías locales; al número de efectivos desplegados, se sumaron 2 mil adicionales. El nuevo operativo buscaba combatir los delitos de secuestro, trata de personas, y la extorsión, además del narcotráfico, poniendo especial atención al puerto de Acapulco. Dos meses después de instalarse Guerrero Seguro, el i2 de diciembre, hubo un enfrentamiento entre normalistas y la policía a la orilla de Chilpancingo, en la Autopista del Sol: el saldo fue de dos muertos y el incendio de la gasolinera Parador del Marqués en donde el encargado de las bombas, Gonzalo Rivas, se sacrificó intentando prevenir una catástrofe mayor. ${ }^{27}$ Ángel Aguirre Rivero destituyó de su puesto al procurador del estado y a tres funcionarios más de seguridad al comprobarse que elementos de la policía habían disparado contra los normalistas.

Con el retorno del PRI a los Pinos la guerra bajó de intensidad, pero la población civil quedó a merced de las células criminales dedicadas fundamentalmente al secuestro y la extorsión, aunque sin abandonar el narcotráfico. El cambio de administración trajo nuevos funcionarios y "nuevas" estrategias de seguridad frente al fiasco de los operativos anteriores, tal como indicaba la cifra negra de la delincuencia. Guerrero ocupaba, en 2ori, el primer lugar en la tasa nacional de secuestro con 3.94 por cada Ioo mil habitantes. Para el año siguiente subió a 4.7I y en 20I3 a 5.87; sin embargo, descendió al tercer escalón del país. En 20II, la extorsión en la entidad suriana registró una tasa de 2.45 casos, ocupando el vigésimo lugar nacional. Para el año siguiente ese delito aumentó 3.8, y para 20I3, creció la tasa a 4.94 extorsiones por cada roo mil habitantes. 
Combatiendo al crimen, en ese año se disponía de 5,484 policías municipales, 2,523 policías ministeriales, aproximadamente 2,ooo policías federales, 9 batallones del Ejército y i batallón de Marina, haciendo un total de alrededor de 16,000 efectivos. .28

El Operativo Especial de Seguridad para Tierra Caliente se anunció el 3 de diciembre de $20 r 4$. Para entonces, se habían dado dos sucesos trágicos en el estado que definieron el sentido de la estrategia: el desastre natural causado por la pareja Manuel e Ingrid y la desaparición forzada en Iguala de 43 estudiantes de la Escuela Normal Isidro Burgos de Ayotzinapa. Así, el operativo no sólo tuvo en la mira combatir la inseguridad regional -no obstante, se enviaron 2 mil efectivos más- en una estrategia integral que incluyó a los vecinos estados de Morelos, Michoacán y Estado de México. Miguel Ángel Osorio Chong afirmó que el operativo retomaba "las acciones que venimos realizando en cuatro entidades de esta región y la reúne en una visión conjunta", anunció también "la construcción de un nuevo cuartel del Ejército en Teloloapan y demás acciones en los municipios de Tierra Caliente". Como respuesta a los sucesos de Iguala, se trabajaría en reforzar a las policías "para evitar su colusión con el crimen organizado". Pero, no obstante que las fuerzas federales se habían hecho cargo de la seguridad en Iguala, el crimen creció en lugar de disminuir. 29

Gráfico 3. Homicidios dolosos en el municipio de Iguala de la Independencia 20II-20I5

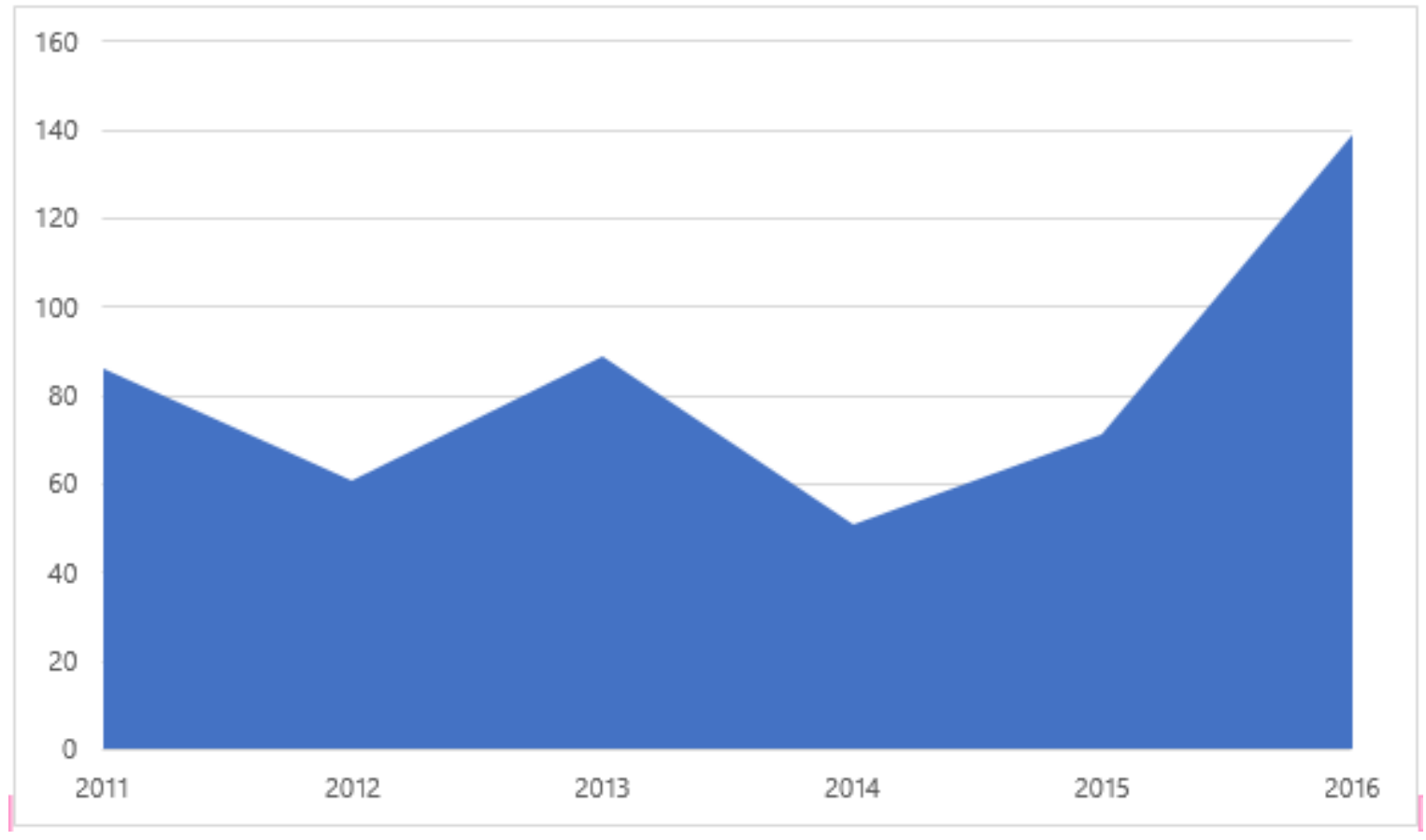

Fuentes: "A dos años de la desaparición de los normalistas, Iguala es más violenta", Animal Político, 26 de septiembre de 2016; "En Guerrero, 2 mil 2r 3 asesinatos en 2016, casi io \% más que en 2015; siguió primero en el pás", El Sur, en línea, 23 de enero de 2017 . 
Guerrero cuenta dos zonas militares: la 27 (El Ticuí) y la 35 (Chilpancingo), esto es, en la entrada de Acapulco y en la capital estatal. Éstas, a su vez, tienen destacamentos (batallones y cuarteles) repartidos en la entidad. Los operativos federales reforzaron la vigilancia con las Bases Operativas Mixtas (BBOOMM), integradas por soldados de las zonas militares respectivas y policías de las distintas corporaciones. Las bboomm tienen el cometido de proteger las zonas urbanas "que presentan problemas de inseguridad" mediante operaciones de vigilancia, revisión vehicular, atención de denuncias ciudadanas e instalación de puestos de seguridad. En 2013 se instalaron I4 bases en Guerrero, I3 en 2014, 3 en 2015 y 28 en 20i6. Pese a los esfuerzos federales, la violencia siguió de manera intermitente en distintas regiones, pero de forma constante en Acapulco. En octubre 2015, como muestra de apoyo al nuevo gobernador priista, Héctor Astudillo Flores, el secretario de Gobernación prometió reforzar a las fuerzas federales ya desplegadas en el estado. Al mando del nuevo operativo (sin nombre) se designó al general Alejandro Saavedra Hernández. En enero de 2016 se implementó un operativo militar para buscar desaparecidos y frenar a grupos criminales. Alrededor de 3,500 militares llegaron a Chilapa de Álvarez, Zitlala y las partes altas de Chilpancingo. Para noviembre del mismo año, otros mil efectivos fueron enviados a varios municipios -Ajuchitán, Arcelia, Teloloapan, Ciudad Altamirano y otros-, con el fin de brindar mayor seguridad a estas comunidades asoladas por los Tequileros. Haciendo un recuento, desde 2013 Guerrero fue la entidad más peligrosa del país al acumular 8,380 homicidios, de enero de aquel año a marzo de 2017, de acuerdo con las estadísticas del Secretariado Ejecutivo del Sistema Nacional de Seguridad Pública. En este tramo, el año más violento fue 2016 con 2,844 asesinatos, si bien bajaron los delitos de secuestro y extorsión respecto de años anteriores. ${ }^{30}$

\section{La sociedad armada}

No podemos pasar por alto en nuestro análisis un tercer actor armado en la guerra irregular en Guerrero: nos referimos a las autodefensas que se formaron cuando alcanzó el cenit la violencia criminal. Cabría distinguir a éstas de la policía comunitaria en los pueblos indígenas de la Montaña que respondió al despliegue del Ejército para contener a la guerrilla eperrista. Con la ocupación militar, fueron constantes los abusos contra la población civil, la violación de los derechos humanos y el pillaje. A diferencia de la guerrilla que buscaba asaltar el poder, la policía comunitaria asumió desde su fundación en i995 y con la Coordinadora Regional de Autoridades Comunitarias (CRAC-PC) en 1998 algunas funciones del Estado (seguridad, justicia), dada la inoperancia de éste. Los elementos de esta policía los designan las comunidades, el cargo suele ser honorario, los milicianos no portan armas por lo general, o éstas son de bajo calibre, y poseen un adiestramiento policial básico operando "con el rostro descubierto, con uniformes que nos identifican como policías comunitarios, con credenciales que avalan el control de nuestras armas". ${ }^{1}$

Las autodefensas ciudadanas poseen una base mestiza y se multiplicaron en toda la entidad conforme creció la violencia criminal. La más importante de éstas, la Unión de Pueblos y Organizaciones Sociales del Estado de Guerrero (UPOEG), empezó como gestora de proyectos sociales y grupo de presión para reducir las tarifas eléctricas. Posteriormente atendió los problemas de seguridad, situación que provocó la desaprobación de la CRAC-PC, "ya que 
estaban utilizando los uniformes de nuestra institución comunitaria, haciendo uso de un discurso que nos es completamente ajeno, ya que como CRAC jamás hemos acordado que nuestras labores está[n] encaminadas a acabar con el narcotráfico". Finalmente, en junio de zorz, los hermanos Bruno y Cirino Plácido Valerio, dirigentes de la UPOEG así como otros de sus miembros, fueron expulsados de la CRAC-PC, por causar división dada su cercanía con el gobernador Aguirre Rivero, quien entregó a la UPOEG poco más de cinco millones de pesos en el primer semestre de 20i3, cuando ésta era todavía ilegal. A su vez, la UPOEG tuvo desprendimientos. De ella surgió el Frente Unido para el Desarrollo y la Seguridad en Guerrero (FUSDEG) que reúne a más de roo comunidades del corredor Acapulco-Chilpancingo. En febrero de 2015, la FUSDEG instaló un retén en Petaquillas, conurbado a Chilpancingo, para encargarse de protegerlo de las bandas criminales que cobraban "piso", secuestraban y provocaron que la gente abandonara sus casas. El conflicto escaló con enfrentamientos frecuentes desde entonces. En marzo, por ejemplo, la comunidad de San Juan del Reparo padeció el enfrentamiento armado entre ambas autodefensas con un saldo de 7 muertos y 9 heridos. 8 muertos en octubre de 2016 cuando la UPOEG intentó tomar el poblado de Tlayolapa, resguardado por FUSDEG. Otra balacera sin víctimas fatales ocurrió en noviembre a la entrada de Tierra Colorada, en poder de esa última. ${ }^{2}$

Como muestran la persecución a la lideresa de la policía comunitaria de Olinalá, Nestora Delgado, y los continuos ataques a la CRAC-PC, comprometida con los movimientos sociales (magisterio, estudiantes de Ayotzinapa), la administración estatal mostró nula simpatía hacia este grupo, el que no pudo subordinar y logró dividir. Con respecto de las autodefensas, la actitud gubernamental ha sido ambigua: reconoce algunas desde 2014, a otras las combate. Y, en su desesperación, algunos empresarios han recurrido a las autodefensas para que los protejan. Sobre algunas autodefensas pende la sospecha de haber sido penetradas por el crimen organizado. Tal es el caso de las autodefensas de la Costa Grande o la UPOEG, legalizada como policía ciudadana por el gobierno de Aguirre Rivero. Después de un enfrentamiento en Chichihualco, en el que la flamante policía ciudadana tuvo varias bajas, una banda criminal acudió al Hospital Raimundo Abarca Alarcón de Chilpancingo para rematar a los heridos, "frente a la sala de urgencias del hospital y desde allí dispararon dos ráfagas de arma de fuego a la fachada". En junio de 20I7. encontraron en Chilpancingo 9 bolsas negras "cuatro cuerpos desmembrados, los cuales fueron arrojados sobre la banqueta de la calle Nueva Secundaria [...] a unos 200 metros de la 35 Zona Militar". En el Zócalo colgaron una cabeza con el consabido narco mensaje. Otra cabeza, pendiente en un paso a desnivel sobre la plaza cívica Primer Congreso de Anáhuac, iba acompañada de una advertencia dirigida a Bruno Plácido. 3

A pesar de disputas y reservas en cuanto a sus propósitos, las autodefensas se extendieron en todo el territorio suriano. Para 20I4, existían organizaciones de este tipo en 47 de los 8I municipios de la entidad, a las que se sumaron muchas más en los siguientes años. Esto da razón de la emergencia en que viven ciudadanos y comunidades que no ven a un Estado capaz de protegerlos o, peor todavía, aliado con los criminales. La situación los ha hecho caminar en el incierto sendero de la justicia por propia mano. En Ayutla de los Libres, por ejemplo, después de un mes y con mucha reticencia, la UPOEG liberó en julio de 2014 únicamente a 4 de los 54 presuntos delincuentes que había capturado. Vecinos de Carrizalillo se negaron a entregar a la 
policía federal a un presunto "halcón" de los Guerreros Unidos en agosto de 20r6, ante la certeza de que la fuerza pública lo dejaría libre. Tres meses antes, en Zitlala, zoo policías comunitarios amagaron con tomar la población para recuperar a la esposa de uno de ellos plagiada por presuntos criminales". El Ejército lo impidió, pero, un año después, no tuvo más remedio que hacerse cargo de la seguridad en la zona "para restablecer el Estado de derecho". ${ }^{4}$

\section{Conclusión}

No puede señalarse una sola causa que explique la persistencia de la violencia en Guerrero, como tampoco es posible decidir cuál de ellas es la principal. Desde luego está la propia conflictividad social, la impunidad, el caciquismo que no ha desaparecido aunado a la corrupción, pero también que los operativos en más de las ocasiones provocan mayor descontrol y penurias a los ciudadanos. Uno de los mayores obstáculos para abatir los índices de criminalidad en el estado es la impunidad secular que deja sin hacer justicia a buena parte de los reclamos ciudadanos. Hay muy pocas detenciones y cuando se hacen denuncias las investigaciones, normalmente, acaban en un callejón sin salida.

Después de io años de violencia imparable, la situación en Guerrero no ofrece cambios sustanciales más allá de declaraciones, operativos y planes ambiciosos. Por si no bastara, también se evidenciaron las graves violaciones a los derechos humanos cometidas por las fuerzas de seguridad en distintos episodios a lo largo de la República, un costo soslayado en el curso de la guerra interna e irregular que sufrimos. Al final de la administración de Peña Nieto los números de la violencia criminal son superiores a los de zor - los peores del sexenio precedente-, con el agravante de que el paciente que recibió gravemente enfermo se había gangrenado. A pesar de que en la entidad participan en labores de seguridad y desmantelamiento de grupos criminales, tanto el Ejército, como las policía federal, estatal y municipal, y en ocasiones la Gendarmería, esto no ha redundado en mayor seguridad. El principio de autoridad parece diluirse en lugar de fortalecerse. Sea una u otra autoridad, las detenciones no aumentan ni se resuelven los casos ya denunciados; a final de cuentas, nadie se hace responsable de hacer justicia. En un inicio, la llegada del Ejército a las poblaciones era recibida con entusiasmo esperando que trajeran seguridad. Pero al correr del tiempo y de varios operativos, tanto la población civil, como los delincuentes, se han adaptado al patrón que se sigue en todos ellos: para los primeros, supone, en el mejor de los casos, unas semanas de tregua en los crímenes y secuestros, pero también se han cometido abusos por parte de los soldados hacia la población civil; para los segundos, un cambio en sus rutas y modus operandi para evitar los retenes, o en el peor de los casos, un desplazamiento hacia alguna población vecina, con lo que se extiende el círculo de la violencia.

Viene bien el concepto de "segurización" para explicar estos resultados, desastrosos para la población civil, pero buenos para los intermediarios, trátese de políticos o criminales. Las estrategias derivadas del poder nominativo de los gobiernos para definir una situación determinada como "cuestión de seguridad", lejos de proporcionar seguridad a la población civil, derecho inalienable, la ponen en riesgo. No es que los sucesivos gobiernos en México se hayan inventado la violencia desatada por los grupos delincuenciales, ésta es real, sino que la manera de combatirla por medio de la militarización ha reforzado los procesos de acumulación de poder 
y despojo que van asociadas al capitalismo trasnacional. Las principales víctimas de la violencia criminal y del combate por parte del Estado pertenecen a la población más vulnerable: desde la clase media de las zonas urbanas, hasta los campesinos más pobres. Los pequeños comerciantes están sujetos al cobro de piso si quieren mantener sus negocios y los campesinos se ven obligados a abandonar sus tierras de cultivo a causa de la violencia. Pero de ambas situaciones se benefician otros, particulares y políticos que se asocian con los grupos criminales y que obtienen enormes ganancias. La militarización sirve a éstos para someter a los grupos inconformes que defienden los bosques, los campos de cultivo, los pequeños o medianos comercios. Éstas son las "consecuencias perversas" del uso de la fuerza armada con el objetivo de lograr la "pacificación" en el país. 35 Persistir en esa estrategia no puede sino seguir reproduciendo la inseguridad y la violencia, extendiendo por tiempo indefinido la guerra.

\section{Archivo}

PGR, Expediente caso Iguala, tomo 20.

\section{Documentos}

"Comunicado de las fundadoras de la Coordinadora Regional de Autoridades Comunitarias", I3 de febrero de 2013 .

"Comunicado de las fundadoras de la Coordinadora Regional de Autoridades Comunitarias", I3 de febrero de 2013 ", 2 de junio de 2013.

International Crisis Group. Justice at the Barrel of a Gun: Vigilante Militias in Mexico, 28 de mayo de 2013 .

Movimiento Revolucionario Lucio Cabañas Barrientos, "Comunicado 5", 28 de junio de 2005.

SEDENA. Informe de labores. México, 2012-2016.

UNDOC. World Drug Report. Market Analysis of Plant-Based Drugs. Opiates, Cocaine, Cannabis. Viena: ONU, 20I7.

Periódicos y portales de noticias

Animal Político, Ciudad de México

El Financiero, Ciudad de México

El País, Madrid

El Sur, Acapulco

El Universal, Ciudad de México 
Excélsior, Ciudad de México

La Jornada, Ciudad de México

Milenio, Ciudad de México

Reforma, Ciudad de México

The Washington Post, Washington D.C.

AGUAYO, Sergio y Raúl BENÍTEZ, coords. Atlas de la seguridad y defensa de México 2016. México: CASEDE, 2017.

AGUILAR CAMÍN, Héctor. "La captura criminal del Estado", Nexos (enero 2015): 19-3I.

AGUILAR V., Rubén y Jorge G. CASTAÑEDA. El narco: La guerra fallida. México: Punto de Lectura, 2009.

AGAMBEN, Giorgio. "El gobierno de la inseguridad". En Pensar desde la izquierda. Mapa del pensamiento crítico para un tiempo de crisis. Christian Laval y otros, 25-35. Madrid: Errata Naturae, 2012.

ASTORGA, Luis. ¿Qué querían que hiciera? Inseguridad y delincuencia organizada en el gobierno de Felipe Calderón. México: Grijalbo, 2015.

BERISTAIN, Carlos Martín. El tiempo de Ayotzinapa. Madrid: Foca, 2017.

CASTELLANOS, Laura. México armado 1943-1981. México: Era, 2007.

COLEMAN, Stephen. Military Ethics. Nueva York: Oxford University Press, 2013.

DE MAULEÓN, Héctor. "Guerreros Unidos", Nexos (febrero 2016): 20-27.

GASPARELLO, Giovanna. "Policía Comunitaria de Guerrero, investigación y autonomía”. Política y Cultura (32) (2009): 6I-78.

GIBLER, John. Una historia oral de la infamia. Los ataques contra los normalistas de Ayotzinapa. México: Grijalbo/Sur+, 2016.

GLEDHILL, John. La cara oculta de la inseguridad en México. México: Paidós, 2017.

GONZÁLEZ RODRÍGUEZ, Sergio. Campo de guerra. Barcelona: Anagrama, 2or4.

GRILLO, Ioan. El narco. En el corazón de la insurgencia criminal mexicana. México: Urano, 2012.

Relaciones Estudios de Historia y Sociedad, vol. XL, núm I57, 2019

268 
GUERRERO GUTIÉRREZ, Eduardo. "Pandillas y cárteles: La gran alianza". Nexos, en línea, I de junio de zoro.

-----_. "La raíz de la violencia". Nexos, en línea, junio de 20 I.

. "El estallido de Iguala". Nexos (noviembre 20I4): 44-47.

------. “Bajó la violencia?”. Nexos, en línea, febrero de 2015.

--_-_. "La segunda ola de violencia". Nexos (abril 20i8): 3I-39.

ILLADES, Carlos y Teresa SANTIAGO. Estado de guerra. De la guerra sucia a la narcoguerra. México: Era, 20I4.

ILLADES, Esteban. La noche más triste. La desaparición de los 43 estudiantes de Ayotzinapa. México: Grijalbo, 2015.

KALDOR, Mary. Nuevas guerras. Violencia organizada en la era global. Barcelona: Tusquets, 200 .

KYLE, Chris. Violence and Insecurity in Guerrero. Washington, San Diego: Woodrow Willson Center, University of San Diego, 2015.

LAVAL, Christian y otros. Pensar desde la izquierda. Mapa del pensamiento crítico para un tiempo de crisis. Madrid: Errata Naturae, 2012.

MARTÍNEZ, Christopher. "Transnational Criminal Organizations. Mexico's Commercial Insurgency", Military Review (2012): 58-62.

MBEMBE, Achille. Necropolítica. Tenerife: Melusina, 20ir.

MIGDAL, S. Joel. Estados débiles, Estados fuertes. México: Fondo de Cultura Económica, 20ir.

PANTOJA, Carlos. "La permanente crisis de Guerrero". En Atlas de la seguridad y defensa de México 2016, coord. Sergio Aguayo y Raúl Benítez, 207-219. México: CASEDE, 2017.

PEREYRA, Guillermo. "México: Violencia criminal y 'guerra contra el narcotráfico", Revista Mexicana de Sociología 74(3) (2012): 429-460.

SÁNCHEZ VALDÉS, Víctor Manuel. "La lucha por el mercado de la droga en Guerrero", Nexos, en línea, i2 de marzo de 2015 .

SANTIAGO, Teresa. Justificar la guerra. México: Miguel Ángel Porrúa, Universidad Autónoma Metropolitana, 200I.

Relaciones Estudios de Historia y Sociedad, vol. XL, núm 157, 2019

269 
SCHEDLER, Andreas. En la niebla de la guerra. Los ciudadanos ante la violencia criminal organizada. México: CIDE, 2015.

TORRE, Wilbert. Narcoleaks. La alianza México-Estados Unidos en la guerra contra el crimen organizado, prólogo de Yuri Herrera. México: Grijalbo, 2013.

Notas

I Rubén Aguilar V. y Jorge G. Castañeda, El narco: La guerra fallida (México: Punto de Lectura, 2009); Carlos Illades y Teresa Santiago, Estado de guerra. De la guerra sucia a la narcoguerra (México: Era, 2014).

2 Véase al respecto Teresa Santiago, Justificar la guerra(México: Miguel Ángel Porrúa, Universidad Autónoma Metropolitana, 200I), rzo y ss.

3 Héctor Aguilar Camín, "La captura criminal del Estado", Nexos (enero 2015): Ig.

4 Andreas Schendler, En la niebla de la guerra. Los ciudadanos ante la violencia criminal organizada (México: CIDE, 20I5), 48-5I.

5 Sergio González Rodríguez, Campo de guerra (Barcelona: Anagrama, 20I4), 3 I.

6 Fue Hillary Clinton quien por primera vez utilizó el término "narcoinsurgencia" para referirse a los grupos violentos dedicados al narcotráfico en México, durante su visita a México en septiembre de 2oro. También adoptó el término Ioan Grillo, El narco. En el corazón de la insurgencia criminal mexicana (México: Urano, 2012), I42. La caracterización como "insurgencia comercial" está en Christopher Martínez, "Transnational Criminal Organizations. Mexico's Commercial Insurgency", Military Review (2012): 59 .

7 John Gledhill, La cara oculta de la inseguridad en México (México: Paidós, 2017), 43; Giorgio Agamben, "El gobierno de la inseguridad", en Pensar desde la izquierda. Mapa del pensamiento crítico para un tiempo de crisis, Christian Laval y otros (Madrid: Errata Naturae, 20I2), 28. Como apunta Yuri Herrera, "un gobernante que, antes que otra cosa, se concibe en tiempos de paz como un jefe policiaco o como un mando militar no puede ser un líder democrático. La lógica de la guerra es incompatible con un régimen democrático". Wilbert Torre, Narcoleaks. La alianza MéxicoEstados Unidos en la guerra contra el crimen organizado, prólogo de Yuri Herrera (México: Grijalbo, 20I3). I3.

8 Mantenemos la misma tesis de Estado de guerra. De la guerra sucia a la narcoguerra (México: Era, 20I4), aunque ahora con mayores precisiones. El término "guerra irregular" lo tomamos de Stephen Coleman, Military Ethics (Nueva York: Oxford University Press, 20iz), i8o; Mary Kaldor, Nuevas guerras. Violencia organizada en la era global (Barcelona: Tusquets, 200I), 202I; Achille Mbembe, Necropolítica(Tenerife: Melusina, 20II), 64. Se citan los dos últimos.

$9 \underline{\text { Stephen Coleman, Military Ethics, } 280 .}$

Relaciones Estudios de Historia y Sociedad, vol. XL, núm 157, 2019 
ı "las fuerzas militares nacionales enfrentan dificultades obvias: frecuentemente no pueden identificar a sus enemigos, [...] [éstos] no portan uniformes, parecen civiles inocentes y prefieren ser combatidos en las comunidades en donde se asientan en gran número ciudadanos realmente inocentes". Nicholas Fotion, War and Ethics (Londres: Continuum, 2007), I22. Cit. en Stephen Coleman, Military Ethics, I8I.

I Eduardo Guerrero Gutiérrez, "Pandillas y cárteles: La gran alianza", Nexos, en línea, i de junio de 2010.

I2 Carlos Illades y Teresa Santiago, Estado de guerra. De la guerra sucia a la narcoguerra. (México: Era, 20I4), 36 y ss.; Laura Castellanos, México armado 1943-1981 (México: Era, 2007), i6o y ss.

I3 Luis Astorga, "Drug Trafficking in Mexico", p. I8. Disponible en http://www.unesco.org/most/astorga.htm (Fecha de consulta: 29 de julio de 20I7).

I4 Guillermo Pereyra, "México: Violencia criminal y 'guerra contra el narcotráfico", Revista Mexicana de Sociología 74(3) (2012): 2; Luis Astorga, ¿Qué querían que hiciera? Inseguridad y delincuencia organizada en el gobierno de Felipe Calderón(México: Grijalbo, 2015), 2I.Se cita el segundo.

I5 Joshua Partlow, "Forget Cliff Divers and Old Hollywood Glamour. Acapulco is Now Mexico's Murder Capital", The Washington Post, en línea, 24 de agosto de 2017; UNDOC, World Drug Report_14, 39; Víctor Manuel Sánchez Valdés, "La lucha por el mercado de la droga en Guerrero", Nexos, en línea, I2 de marzo de 20I5; Chris Kyle, Violence and Insecurity in Guerrero (Washington, San Diego: Woodrow Willson Center, University of San Diego, 2015), i8. Se cita el penúltimo.

I6 Eduardo Guerrero Gutiérrez, "La segunda ola de violencia", Nexos (abril 2018): 33; "Termina huelga de policías de Acapulco; cae Alfredo Álvarez", El Sur, en línea, i de mayo de 20r4; Joshua Partlow, "Forget Cliff Divers". Se cita éste.

I7 Chris Kyle, Violence and Insecurity, 20; Joshua Partlow, "Forget Cliff Divers"; Guillermo Pereyra, "México: Violencia criminal", 6. Se cita éste.

I8 Eduardo Guerrero Gutiérrez, "El estallido de Iguala", Nexos (noviembre 20I4): 46; Carlos Pantoja, "La permanente crisis de Guerrero", en Atlas de la seguridad y defensa de México 2016, coords. Sergio Aguayo y Raúl Benítez (México: CASEDE, 20I7), 2iz y ss.; Víctor Manuel Sánchez Valdés, "La lucha por el mercado de la droga en Guerrero", Nexos, en línea, i2 de marzo de 20I5; "Ola violenta en Guerrero por división de cárteles", Milenio, en línea, I5 de marzo de 20I7. Las políticas neoextractivistas echaron raíces en Guerrero con el ascenso neoliberal. Tierras, bosques y subsuelo alimentaron el apetito de los conglomerados transnacionales formando el contexto ineludible del teatro de la guerra en la entidad. Guerra también contra las comunidades locales que trataban de preservar los recursos e impedir la privatización desbocada de los bienes públicos con la aquiescencia de un Estado rentista. El oro representaba, en 20r3, el 26 \% de la producción de la minería en México, situándose Guerrero en quinto lugar en este rubro. La 
canadiense Goldcorp, la tercera corporación aurífera más importante del planeta con enclaves en Zacatecas (Concepción del Oro) y Durango (Tlayotitla), llegó a Mezcala en 2007 arrendando el predio de los ejidatarios de Carrizalillo, en el municipio de Eduardo Neri. No obstante, el bajo nivel salarial en Guerrero abonó para que campesinos y técnicos especializados se incorporaran a la minería donde, según la cámara del ramo, la remuneración salarial es 4I \% superior a la media nacional. Esto convirtió a los trabajadores en blanco de las bandas delincuenciales para el cobro de piso, con el consecuente amedrentamiento, los secuestros y la ola de asesinatos. De acuerdo con una estimación de la comunidad, "el crimen se lleva entre izo y 150 millones de pesos anuales". "Carrizalillo, entre crimen y abandono", El Universal, en línea, I3 de noviembre de 2015 .

I9 Chris Kyle, Violence and Insecurity, 32-33; Esteban Illades, La noche más triste._La desaparición de los 43 estudiantes de Ayotzinapa(México: Grijalbo, 2015), 40; "Aprehenden a líder de Guerreros Unidos", Milenio, I de mayo de 20I4; Héctor de Mauleón, "Guerreros Unidos", Nexos (febrero 20I6): 20-2I; PGR, Expediente caso Iguala, t. 20, f. gI; "Detienen a jefes del Cártel Independiente de Acapulco y de Guerreros Unidos", El Sur, en línea, i4 de enero de 2016.

20 PGR, Expediente caso Iguala, t. 20, ff. 89, II3, I32; Chris Kyle, Violence and Insecurity, 29-30; "PF detiene en Querétaro a la presunta líder de los Rojos", El Universal, en línea, 6 de marzo de 20I4; “¿Quién es la lideresa de los Rojos?; la ligan con Beltrán Leyva”, El Universal, en línea, 7 de marzo de 20i4. Se cita el primero.

2I "Hallan cuerpos de 6 de los 8 'levantados' en Mochitlán, Guerrero", Milenio, en línea, I de febrero de 20I7; "Vuelve a invadir el pánico al pueblo de Chacotla", El Universal, en línea, 4 de febrero de 20I7; "Encuentran cuatro cadáveres en carretera de Guerrero", Milenio, en línea, 23 de abril de 2017; "Líder del congreso de Guerrero es hermano de narcos", El Financiero, en línea, 26 de mayo de 20I5; Héctor de Mauleón, “QQuiénes diablos son 'los Ardillos”, El Universal, en línea, 6 de noviembre de 2015 .

22 "Toman Chilapa grupos armados", Reforma, io de mayo de 2015; "Civiles desarman a policía en Chilapa", Milenio, en línea, 9 de mayo de 2015; "Paraliza a Chilapa comando armado", Reforma, I3 de mayo de 2015; "Chilapa de Álvarez: reportan i2 'levantados' en sólo una semana", La Jornada, I7 de mayo de 2015; "Taxistas y carniceros, entre los 'levantados' en Chilapa”, Milenio, en línea, 20 de mayo de 2015; "Los Ardillos, el verdadero poder en Chilapa", Proceso, 3i de mayo de 20i5; "Los Ardillos y los Rojos, responsables de la desaparición de i6 personas en Chilapa", La Jornada, en línea, 24 de mayo de 2015; "Crece en Chilapa tensión por narco", Reforma, I4 de mayo de 20I5; "Dejan Chilapa civiles armados", Reforma, I5 de mayo de 2015; "Comisario de Chilapa asegura que entregaron detenidos a policías", Milenio, en línea, 28 de mayo de 20I5; "El narco, telón de fondo de los desaparecidos en Chilapa", La Jornada, 3i de mayo de 20r5; "Aparece muerto funcionario secuestrado en Chilapa", Milenio, en línea, i de septiembre de 2or6; "Chilapa cumple dos años bajo la violencia", El Universal, en línea, i2 de mayo de 2017; "Hacen leva Ardillos en Chilapa, denuncian", Reforma, 28 de mayo de 2015. Se citan los dos últimos. 
23 Chris Kyle, Violence and Insecurity, 26-27; "El Tequilero, sicario que ha ejecutado a líderes partidistas y ediles en Guerrero", El Financiero, en línea, 26 de enero de 20r6; "Embestida de los Tequileros causa violencia en Guerrero", Milenio, en línea, 23 de noviembre de 2016.

24 "En I5 minutos, 6oo disparos contra el edil de Pungarabato, Guerrero", Milenio, en línea, 27 de julio de 20r6; "Matan en una emboscada al alcalde de Pungarabato, Ambrosio Soto Duarte", El Sur, en línea, 24 de julio de 20r6; "Liberan al regidor de Seguridad de Totolapan", El Universal, en línea, 4 de septiembre de 2or6; "Realizan secuestro masivo en Guerrero", El Universal, en línea, I9 de noviembre de 20i6; Pablo Ferri, "De cerro en cerro, cautivos de los Tequileros en México", El País, en línea, 2i de noviembre de 20i6; "Mamá del Tequilero, pide entregar a ingeniero", Milenio, en línea, i4 de diciembre de 20ı6; "Pidieron 3 millones por mí, afirma ingeniero", Milenio, 16 de diciembre de 2016; "Liberan a 20 Tequileros; fiscalía indaga a cuatro", Milenio, en línea, I7 de diciembre de 20ı6; "Alcalde de Teloloapan deja municipio por amenazas", Milenio, en línea, 27 de abril de 20I7; "Irrumpe el Tequilero en pueblos de Totolapan; amenaza con matarlos si no lo apoyan, dicen", El Sur, en línea, 9 de mayo de 2017.

25 "Cacique 'compra' tierras a sangre y fuego en la sierra de Petatlán", La Jornada Guerrero, en línea, I4 de marzo de 2007; Movimiento Revolucionario Lucio Cabañas Barrientos, "Comunicado 5", 28 de junio de 2005; Chris Kyle, Violence and Insecurity, 24; "Capturan a Rogaciano Alba, ligado al Chapo", El Universal, en línea, i2 de febrero de 2oro; Asedia crimen corredor turístico Tierra Caliente", El Universal, en línea, 26 de julio de 2016.

26 "Desde 2007 llegaron las fuerzas federales a Guerrero", Milenio, en línea, I5 de diciembre de 20ı6; "La nueva estrategia anticrimen, después de tres que en 8 años no pudieron contra la violencia", El Sur, en línea, 3 de octubre de 2015. Se cita éste.

27 "Desde 2007 llegaron fuerzas federales a Guerrero", Milenio, en línea, I5 de noviembre de 20i6; "Chocan policías y normalistas en Chilpancingo; 2 muertos", El Universal, en línea, i2 de diciembre de 20II.

28 "Guerrero después de Guerrero Seguro", Milenio, en línea, 6 de octubre de 2014; Chris Kyle, Violence and Insecurity, 35-37.

29 "Envían refuerzos a Tierra Caliente; garantizarán libre tránsito en vías de comunicación", Excélsior, en línea, 4 de diciembre de 20I4. Sobre la desaparición de los estudiantes véanse Esteban Illades, La noche más triste. La desaparición de los 43 estudiantes de Ayotzinapa(México: Grijalbo, 2015); John Gibler, Una historia oral de la infamia. Los ataques contra los normalistas de Ayotzinapa (México: Grijalbo/Sur+, 2016); Carlos Martín Beristain, El tiempo de Ayotzinapa (Madrid: Foca, 20I7).

3o SEDENA, Informe de labores, 20i2-20i6; "La violencia que no cesa en Guerrero", El País, 30 de enero de 2015; "Desde 2007 llegaron las fuerzas federales a Guerrero", Milenio, en línea, i5 de diciembre de 20r6; "Guerrero es la entidad más peligros al sumar 8 mil 380 homicidios desde 2013", El Universal, en línea, 25 de abril de 20i7; Secretariado Ejecutivo del Sistema Nacional de 
Seguridad Pública, https://www.gob.mx/sesnsp (Fecha de consulta: 8 de agosto de 20I7). Se cita el primero.

3I "Comunicado de las comunidades fundadoras de la Coordinadora Regional de Autoridades Comunitarias", 2 de junio de 20i3; Giovanna Gasparello, "Policía Comunitaria de Guerrero, investigación y autonomía", Política y Cultura (32) (2009): 66; International Crisis Group, Justice at the Barrel of a Gun: Vigilante Militias in Mexico, 28 de mayo de 20Iz: 9; José Salgado, "Policías comunitarias y grupos de autodefensa", La Jornada del Campo, suplemento de La Jornada, I8 de mayo de 20iz. Se cita éste.

$3^{2}$ Comunicado de las comunidades fundadoras de la Coordinadora Regional de Autoridades Comunitarias", I3 de febrero de 2013; "Expulsa la CRAC-PC de sus filas a los hermanos Bruno y Plácido Valerio", La Jornada, 28 de junio de 2013; "Muchas armas listas para disparar", Proceso, 29 de diciembre de 20r3; "Crece tensión en Petaquillas", Reforma, 3 de febrero de 2015; "La policía comunitaria de Petaquillas, respuesta al "embate delincuencial", La Jornada, 8 de febrero de 2015 ; "Mantiene el Ejército dos retenes cerca de Petaquillas que instaló tras la entrada de la policía comunitaria", El Sur, ro de febrero de 2015; "Los campesinos que se levantaron en armas a i2 kilómetros de Chilpancingo", Milenio, in de febrero de 20I5; "Liberan a i comunitarios", Reforma, 4 de abril de 2015; "Balacera entre comunitarios deja 8 muertos en Guerrero", Milenio, en línea, 25 de octubre de 20i6; "Marchan contra conflicto entre comunitarios en Guerrero", El Universal, en línea, I3 de noviembre de 2016; "Policías comunitarios se enfrentan a balazos en Tierra Colorada", El Universal, en línea, 24 de noviembre de 2or6; "Guerrero, sin justicia, sin dinero, sin gobierno...", Proceso, 20 de noviembre de 20i6. Se cita el primero.

33 "Fracción de Eliseo Villar toma Casa de Justicia de la CRAC en San Luis Acatlán", La Jornada, I3 de abril de 2or4; "Desarman soldados a mando de la CRAC y a 6 guardias en Guerrero", La Jornada, 28 de junio de 2013; "Detienen militares a 3i miembros de la CRAC-PC, incluido el líder", La Jornada, 23 de agosto de 2013; "Militares detienen a ro policías comunitarios en Ayutla de los Libres; van 29 en dos días", La Jornada, 24 de agosto de 2or3; "En Chilpancingo, alianza de COPARMEX con sistema ciudadano de defensa", La Jornada, I8 de junio de 20I3; "Policías ciudadanos toman comunidades en Chilpancingo", La Jornada, 24 de enero de 20r4; "Las autodefensas de Guerrero reclaman la atención del gobierno", El País, en línea, 30 de enero de 2014; "Marchan más de 2 mil personas en Chilpancingo; reclaman protección", La Jornada, en línea, 30 de enero de 2014; "Autodefensas de la Costa Grande, "ligadas a grupos criminales", La Jornada, 4 de julio de 20i3; "Policías comunitarias de Guerrero se acusan de narcos", Milenio, en línea, I4 de noviembre de 20r6; "Atacan el Hospital General de la capital para rematar a policías de la UPOEG heridos en Chichihualco", El Sur, en línea, 7 de noviembre de 2015; "En 72 horas asesinan a I8 personas en Chilpancingo", El Universal, en línea, 5 de junio de 20I7. Se citan los dos últimos.

34 "Grupos de autodefensa de Ayutla inician entrega de reos", Proceso, en línea, 6 de julio de 20I4; "Surge grupo de autodefensa en Tlacotepec, Guerrero", Milenio, 8 de mayo de 2or7; "Crean en Guerrero grupo de autodefensas; exigen seguridad", El Universal, en línea, 28 de mayo de 20I7; "Surge en Guerrero la 'Guardia Rural de los Ejidos", Milenio, en línea, i8 de julio de 20r7; "Hay 
pobladores con armas en $65 \%$ de Guerrero", Milenio, en línea, 28 de agosto de 20I7; "Ponen en venta la mina de oro y plata Los Filos, de Carrizalillo, la empresa canadiense Goldcorp", El Sur, en línea, 5 de agosto de 20i6; "Irrumpen en Zitlala, Guerrero, 300 comunitarios; buscan a plagiada", Milenio, en línea, 4 de mayo de 20r6; "Ejército asume seguridad en poblado de Zitlala, Guerrero", Milenio, en línea, 5 de julio de 2017.

35 John Gledhill, La cara oculta, 2or.

\section{Teresa Santiago}

Es doctora en Filosofía Política (UAM-I), profesora titular del Departamento de Filosofía de la UAM-Iztapalapa e investigadora nacional nivel II del SNI. Es autora de La guerra humanitaria. Pasado y presente de una controversia filosófica (2013); Estado de guerra. De la guerra sucia a la narcoguerra (2014, en colaboración con Carlos Illades); y Bárbaros contra cristianos, la polémica Bartolomé de las Casas-Juan Ginés de Sepúlveda (20r8). Especialista en filosofía del conflicto, la guerra y la violencia política y filosofía moderna (Kant, Rousseau, Hobbes). Dirigió la revista Signos Filosóficos.

\section{Carlos Illades}

Es profesor titular del Departamento de Humanidades de la Universidad Autónoma Metropolitana, Unidad Cuajimalpa, investigador nacional nivel 3 del SNI, miembro de la Academia Mexicana de Ciencias, sillón número ro de la Academia Mexicana de la Historia y profesor distinguido de la UAM. Premio de investigación de la Academia Mexicana de Ciencias (1999), es autor de La inteligencia rebelde. La izquierda en el debate público en México, 19681989 (2012); De La Social a Morena. Breve historia de la izquierda en México (2014); Conflicto, dominación y violencia. Capítulos de historia social (2015, traducido al inglés en 20I7); El futuro es nuestro. Historia de la izquierda en México (2018); y El marxismo en México. Una historia intelectual (2018). Coautor, con Teresa Santiago, de Estado de guerra. De la guerra sucia a la narcoguerra (2014). Se especializa en historia social, historia de la izquierda e historia del pensamiento socialista. 